\title{
Highly Regio-Selective Synthesis of $\beta$-Amino Alcohol by Reaction with Aniline and Propylene Carbonate in Self Solvent System over Large Pore Zeolite Catalyst
}

\author{
Anil K. Kinage ${ }^{1}$, Pravin P. Upare ${ }^{1}$, Anandkumar B. Shivarkar ${ }^{2}$, Sunil P. Gupte ${ }^{2 *}$ \\ ${ }^{1}$ Catalysis Division, National Chemical Laboratory, Pune, India \\ ${ }^{2}$ Chemical Engineering Division, National Chemical Laboratory, Pune, India \\ E-mail:"sp.gupte@ncl.res.in \\ Received April 7, 2011; revised May 13, 2011; accepted May 25, 2011
}

\begin{abstract}
The nucleophilic ring opening of epoxides with amines is a well known route for the synthesis of $\beta$-amino alcohols. The use of carbonates offers significant advantages over epoxides as they are far less hazardous materials, safe for handling, do not require high-pressure equipment and most notably the possibility of solvent less reactions. In this work, utilization of zeolite as host catalyst in the reaction media for synthesis of $\beta$-amino alcohols without using solvent is reported.
\end{abstract}

Keywords: $\beta$-Amino Alcohol, Proplylene Carbonate, Zeolite, Catalyst, Chemo-Selectivity

\section{Introduction}

$\beta$-Amino alcohols are used as intermediates in the synthesis of wide range of biologically active natural and synthetic products [1-3] unnatural amino acids $[4,5]$ and asymmetric synthesis as chiral auxiliaries [6]. The nucleophilic ring opening of epoxides with amines group is a well known route for the synthesis of $\beta$-amino alcohols [7-11]. Generally, in the classical method the cleavage of epoxides is achieved by treatment with excess of amine at suitable temperature. However, the lack of appreciable selectivity, the requirements of high temperature and the need of excess amine in the classical methods have led to the necessity for activation of the epoxides so as to increase their susceptibility to nucleophilic attack by amine.

The various methodologies developed for this include the use of alumina [12], metal amides [13-15], metal alkoxides [16], metal triflates [17-19], transition metal halides [20,21], alkali metal perchlorates [22], rare earth metal halides [23-25] and silica under high pressure [26]. However, these methodologies suffer from one or more disadvantages such as long reaction times, elevated temperatures, moderate yield, use of air and/or moisture sensitive catalysts, requirement of stoichiometric amounts of expensive reagents/catalysts, potential rearrangement of allylic alcohols [27] potential hazards in handling pyrophoric/moisture sensitive reagents in the preparation of the catalyst, and in most cases applicable to aromatic amine only as aliphatic amines often deactivate the organometallic catalyst.

Considering the widespread applications of the resultant $\beta$-amino alcohols, we felt that not only a catalyst choice should be one that is easily available and less expensive, less toxic and operatable under environmentally friendly conditions so as to fulfill the triple bottom line philosophy of green chemistry, but also to develop a more efficient approach for the synthesis of $\beta$-amino alcohols that will lead a new technology. The applications of cyclic carbonates in synthesis of fine chemicals are reviewed recently [28]. The use of carbonates offers significant advantages over epoxides as they are far less hazardous materials, safe for handling, do not require high-pressure equipment and most notable thing is the possibility of solvent less reactions with carbonates as it itself act as solvent in reaction medium [28].

Zeolites can be used for fine chemical synthesis, which is highlighted in a review [29,30]. A choice of solvent is necessary for complete conversion and high yield as the products can be desorbed easily from zeolitic pore and solvent should not compete with the reactant in adsorption process [31]. The feasibility of using $\mathrm{Na}-\mathrm{Y}$ as catalyst for synthesis of amino alcohols from aniline (AA) and propylene carbonate (PC) has been shown earlier; however, detail study on effect of catalysts and reaction 
parameters on the regio and stereo selectivity of product was not reported [32]. We describe here a practical approach that is highly regio selective for synthesis of 1(phenylamino) propan-2-ol (3) from propylene carbonate and aniline using a solvent less system, and zeolite as recyclable heterogeneous catalyst (Scheme 1). The route is thus aligning with the green chemistry approach.

\section{Results and Discussion}

When aniline and propylene carbonate in a molar ratio of 1:1 was stirred along with $\mathrm{Na}-\mathrm{Y}$ zeolite $(100 \mathrm{mg})$ in a round bottom flask at $150^{\circ} \mathrm{C}$, mono substituted $N$-alkylated product, 1-(phenylamino) propan-2-ol (Scheme 1) was formed with $>95 \%$ selectivity (analyzed by gas chromatographic). The concentration-time plots for aniline (AN) and $\beta$-amino alcohol (AA) at $150^{\circ} \mathrm{C}$ and $180^{\circ} \mathrm{C}$ respectively is shown in Figure 1. Solvent less system often results in poor yields due to deactivation of active site by reactant and product molecules. The high concentration of reactants and products many times results in slow reaction due to diffusional resistance, however, in our system even 1:1 moles of reactants results in complete conversion with high regio-selectivity of desired product (3) (See Figure 1). Continuous increase in the formation rate of product makes our system highly precious. These observations support that the propylene carbonate can be best used as self solvent in the reaction medium. The $\mathrm{Na}-\mathrm{Y}$ zeolite as catalyst of the reaction can be reused with fresh aniline and propylene carbonate with a high conversion of aniline $\sim 80 \%$ and yields of 1-(phenylamino) propan-2-ol $\sim 75 \%$ even after 5 recycles.

The effect of temperature on the activity and selectivity of the reaction was studied and results are shown in Figure 2. The results show that the $150^{\circ} \mathrm{C}$ reaction temperature is suitable to achieve high region-selective product. Further increasing reaction temperature increases conversion but the regio-selectivity of product decreases (See also Figure 1). Therefore, for all further studies we used $150^{\circ} \mathrm{C}$ as reaction temperature and $48 \mathrm{~h}$ as reaction period.

A reaction pathway is shown in Schemel (Route I and II), wherein $\mathrm{CO}_{2}$ is evolved as a by product. Since, the reaction of $\mathrm{CO}_{2}$ with propylene glycol is known to give propylene carbonate $[33,34]$, the proposed route becomes even more valuable. The transformation of aniline to regio-selective 1-(phenylamino) propan-2-ol is achieved through zeolitic framework. A mechanism involving nucleophilic attack of aniline on sterically less hindered carbon from propylene carbonate by the loss of $\mathrm{CO}_{2}$ to form active carbonium ion intermediate.

Zeolitic framework plays vital role in formation of

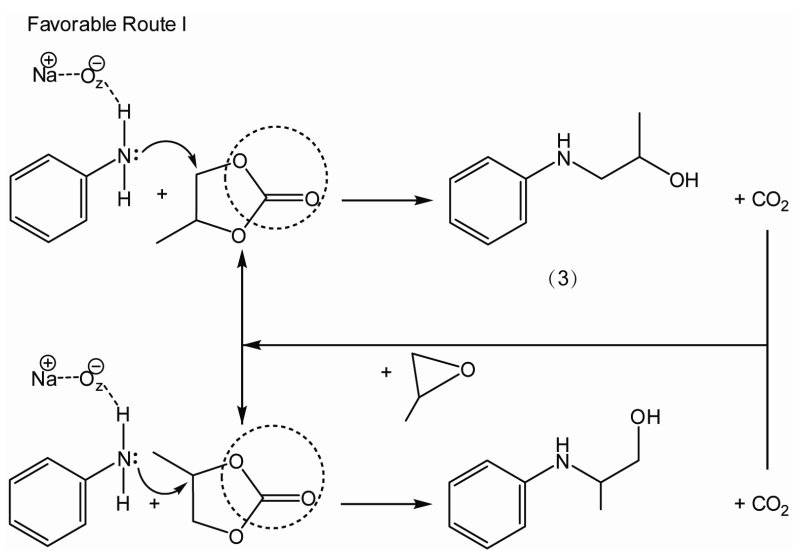

Less favorable Route II

(4)

Scheme 1

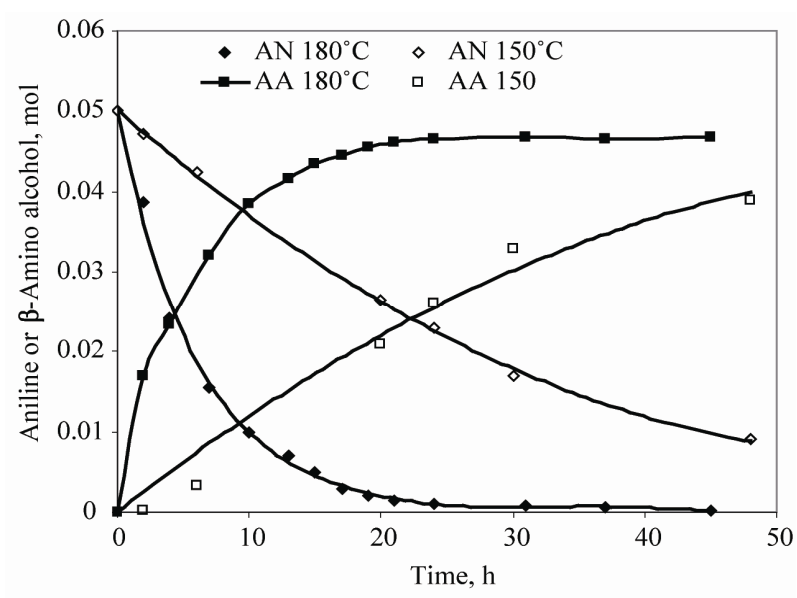

Figure 1. Synthesis of amino alcohol using $\mathrm{Na}-\mathrm{Y}$ zeolite.

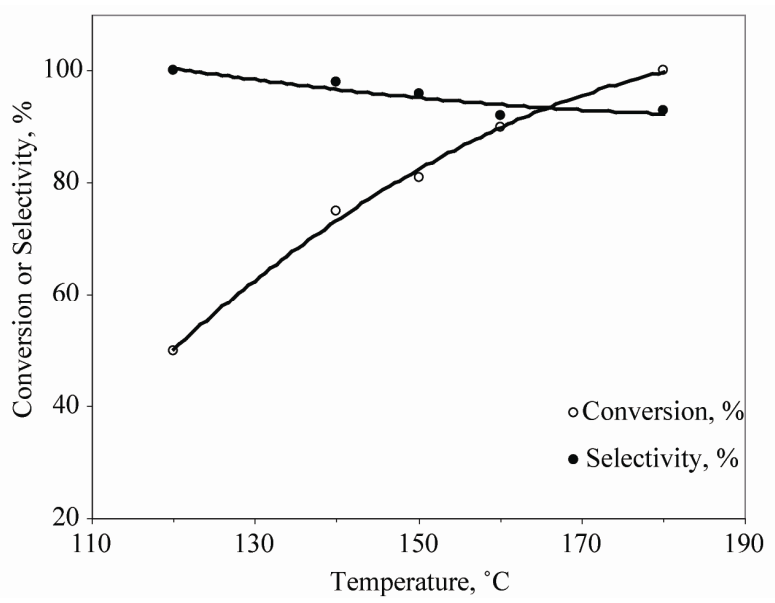

Figure 2. Effect of temperature on activity and selectivity of 1-(phenylamino)propan-2-ol (aniline/propylene carbonate : 1:1 mole, reaction time $=48 \mathrm{~h}$ ).

chemo-selective 1-(phenylamino) propan-2-ol product through route-I as zeolitic framework has characteristic 
feature of shape selectivity, which leads to a selective product based on molecular shape. The zeolite $\mathrm{Y}$ has a framework of basic and cationic sites which act as Lewis base and conjugated Lewis acid pairs [35]. It is likely that benzene ring in aniline is adsorbed on the $12 \mathrm{R}$ windows of Na-Y structure on Lewis acidic sites of $\mathrm{Na}-\mathrm{Y}$ zeolite as shown earlier [36], such location was proposed for aniline in $\mathrm{Na}-\mathrm{Y}$ from neutron diffraction study, the $\mathrm{NH}_{2}$ group in aniline molecules are held in the center of super cage of Na-Y zeolite by Van der Waals interaction and benzene ring was adsorbed on 12R window of Na-Y framework, which is slightly tilted out from the oxygen plane of the $12 \mathrm{R}$ window as its Van der Waals radius (Max. $\sim 7.6 \AA$ ) is too large to fit perfectly into the $12 \mathrm{R}$ window [37]. Therefore, $\mathrm{NH}_{2}$ group in aniline will be above the ring plane formed by the oxygen and may protrude in the super cage where it interacts strongly with the large electric field associated with the carbon/framework of oxygen. The carbonium ion (active intermediate of the reaction formed by route I and II, Scheme 1) formed on basic sites of Na-Y from propylene carbonate attacks the active hydrogen from $\mathrm{NH}_{2}$ group leading the formation of $N$-(phenylamino) propan-2-ol. The example of this is shown in Scheme 1.

Increase of Brønsted acidity of the Na-Y zeolite (increase of $\mathrm{H}^{+}$form) decrease the catalytic activity of reaction as shown in Table 1 (Sr.no. 1 - 5), which further supports our view that Lewis acid-base pairs are responsible for a good activity of catalyst. Thus the Lewis acid and Lewis base in Na-Y zeolite together play an important role in achieving high conversion and high regioselective ring opening reaction between propylene carbonate and aniline. To understand the role of different alkali metal ions, we exchanged the $\mathrm{Na}-\mathrm{Y}$ with $\mathrm{K}$ and $\mathrm{Cs}$ ions and the results are shown in Table 1 (Sr.no. 6 - 7). The conversion and selectivity of product decreased by increase in size of alkali cation exchange $(\mathrm{Na}<\mathrm{K}<\mathrm{Cs})$, this may be because of hindrance for the benzene ring adsorption on 12R window of $\mathrm{Y}$ zeolite. By exchanging Cs the basicity of catalyst increases and highly basic character of the catalyst does not seem to favor the reaction. For understanding the role of basicity, few more experiments were conducted using Lewis base and nonzeolite catalysts such as TEA-Br, Na-Aluminates, $\mathrm{Mg}$ Al (3:1) hydrotalcite, $\mathrm{MgO}, \mathrm{NaCl}$. Few more experiments were carried out separately using non zeolite catalysts. With these catalysts lower conversion and lower regio-selectivity for the alkylation reaction is observed and results are shown in Table 1, Sr.no. 8 - 12. In contrast to the result with zeolite Na-Y (see Table 1, Sr.no. 1) in which both basic and acidic sites is available. This aspect was further explored in order to quantify and identify the nature of acid and base sites in NaY. The
Table 1. Activity over zeolites, alkali exchange zeolites and non zeolite catalysts.

\begin{tabular}{|c|c|c|c|c|c|}
\hline $\begin{array}{l}\text { Sr. } \\
\text { No. }\end{array}$ & Catalyst & $\begin{array}{c}\mathrm{Al} /(\mathrm{Al}+\mathrm{Si}) \\
\text { ratio }\end{array}$ & $\begin{array}{c}\mathrm{Na}^{+} \\
\text {form, }(\%)\end{array}$ & $\begin{array}{c}\text { Conv., } \\
(\%)\end{array}$ & $\begin{array}{c}\text { Yield, }^{\mathrm{a}} \\
(\%)\end{array}$ \\
\hline 1 & $\mathrm{Na}-\mathrm{Y}$ & 0.29 & 100 & 80.5 & 79.9 \\
\hline 2 & $\mathrm{NaH}-\mathrm{Y}$ & 0.29 & 82 & 35.3 & 33.9 \\
\hline 3 & $\mathrm{NaH}-\mathrm{Y}$ & 0.29 & 45 & 27.1 & 25.9 \\
\hline 4 & $\mathrm{NaH}-\mathrm{Y}$ & 0.29 & 10 & 24.2 & 21.6 \\
\hline 5 & $\mathrm{H}-\mathrm{Y}$ & 0.29 & 0 & 23.8 & 20.1 \\
\hline 6 & $\mathrm{~K}-\mathrm{Y}$ & 0.29 & 100 & 74.4 & 73.3 \\
\hline 7 & Cs-Y & 0.29 & 100 & 69.2 & 67.8 \\
\hline 8 & Na-Alumin-ate & - & - & 42.2 & 21.4 \\
\hline 9 & $\begin{array}{c}\text { Mg-Al } \\
\text { Hydrotalcite }\end{array}$ & - & - & 41.7 & 32.8 \\
\hline 10 & TEA-Br & - & - & 48.3 & 40.9 \\
\hline 11 & $\mathrm{MgO}$ & - & - & 5.0 & 4.5 \\
\hline 12 & $\mathrm{NaCl}$ & - & - & 15.1 & 14.0 \\
\hline 13 & Na-MOR & 0.15 & 100 & 13.4 & 12.9 \\
\hline 14 & $\mathrm{Na}-\mathrm{L}$ & 0.24 & 100 & 12.2 & 11.1 \\
\hline 15 & Na-ZSM-5 & 0.03 & 100 & 17.1 & 16.0 \\
\hline
\end{tabular}

a.Temperature: $150^{\circ} \mathrm{C}$; Time: $48 \mathrm{~h}$; AN/PC ratio: 1:1 mole: mole.

nature of acid and base sites of $\mathrm{NaY}$ zeolite catalyst used in the present work was characterized by some of us earlier [38] by using $\mathrm{NH}_{3}$ and $\mathrm{CO}_{2}$ TPD as well as by pyridine adsorption followed by FT-IR analysis. The characterization data showed a marked difference in the nature of acidic and basic active sites of $\mathrm{NaY}$ zeolite which is revealed by $\mathrm{NH}_{3}$ and $\mathrm{CO}_{2}$ TPD. It was observed from TPD analysis that there exist smaller surface density of acidic sites compared to basic sites in $\mathrm{NaY}$ (base to acid ratio 6.25 [38]) indicating that Lewis basicity due to framework oxygen atoms seems to be playing a main role in substrate activation, while on the other hand Lewis acidity is essential but seems to be less important in this case. Nevertheless combination of Lewis acid-base properties is preferred for an efficient catalysis. In this context, it may be noted that in aminolysis of epoxides over solid acid catalysts, catalytic activity decreased with increasing basicity of the amines, presumably due to deactivation of acidic sites of catalyst by amine [39].

Further, the reaction of aniline and propylene carbonate carried out over different zeolites (Na-ZSM-5, NaMordenite and Na-L) gives different conversion and selectivity of the 1-(phenylamino) propan-2-ol as shown in Table 1, Sr. no. $13-15$. The aniline in different zeolitic framework adsorb with different molecular orientation. The Na-Y zeolite may be suitable for this reaction as the active $\mathrm{NH}_{2}$ group of aniline adsorbed in $\mathrm{Na}-\mathrm{Y}$ is located in super cage and which is easily accessible as an alkylating group formed by propylene carbonate with particular shape leading to regio-selective 
formation of 1-(phenylamino) propan-2-ol. Consistent with these mechanistic schemes, the overall yield of alkylation is highly dependent on the ring size and substitution pattern of the zeolite framework.

In order to extend the usefulness of this protocol further, optically pure enanatiomer (R or S, $98 \%$ ee by GLC, and used as received from Aldrich, USA) of propylene carbonate was allowed to react with aniline and the results are represented in Table 2. Reaction of (R or S) 1,2-propylene carbonate $(\sim 98 \%$ ee) with aniline gave four possible chiral $\beta$-amino alcohols illustrated in Table 2. As expected, an excellent selectivity of (2R)-1-(phenylamino) propan-2-ol or (2S)-1-(phenylamino) propan2-ol is obtained with yields, 96:4 (3:4) in favor of nucleophilic attack of amine at the sterically less hindered methylene carbon of 1,2 propylene carbonate (Table $2 \mathrm{Sr}$. no. 1 and 2). Two isomers viz. 1-(phenylamino) propan2-ol (3) showed the characteristic ion peak at $\mathrm{m} / \mathrm{z} \mathrm{M}^{+}-45$ due to loss of $\mathrm{CH}_{3} \mathrm{CHOH}$ where as, 2-(phenylamino) propan-1-ol (4) showed the ion peak at $\mathrm{m} / \mathrm{z} \mathrm{M}^{+}-31$ due to loss of $\mathrm{CH}_{2} \mathrm{OH}$ in mass spectra [40]. Thus it was observed that chiral amino alcohol can be synthesized using stable chiral 1,2-propylene carbonates.

\section{Conclusions}

High activity and high selectivity for synthesis of 1(phenylamino) propan-2-ol is achieved over recyclable $\mathrm{Na}-\mathrm{Y}$ zeolite. It has been shown that Lewis acid-base pairs play an important part in activity of a catalyst. The halide free and solvent free reaction of aniline and propylene carbonate is a clean, safe, and reproducible, method that uses less hazardous materials and does not require high pressure equipments usually required in ring opening reaction of epoxide by aniline. The synthesis method proposed here could impose practical value in the common applications for a wide range of amino alcohol derivates. No operational problems that are foreseen for the large-scale version of this green approach. Synthesis process and technical refinement should further increase the synthetic regio-selectivity of the mono 1-(phenylamino)propan-2-ol product, which of great interest in medicinal, biological active synthetic and natural product, artificial amino acids, and chiral auxiliaries for asymmetric synthesis. Finally, it was also shown that starting from chiral carbonates; chiral $\beta$-amino alcohols can be synthesized retaining high ee value.

\section{Experimental}

\subsection{Materials}

Aniline and propylene carbonate were purchased from either S.D. fine chemical Ltd. India or Aldrich, USA. Zeolite Na-Y was provided by Süd-Chemie, India, other zeolites such as, K-Y, Cs-Y, Na-MOR, Na-L and NaZSM-5 already synthesized and well characterized in our laboratory were used as such $[41,42]$.

\subsection{Typical Reaction Procedure}

Typical procedure used for production of 1-(phenylamino)propan-2-ol from propylene carbonate and aniline is as follows. In a $20 \mathrm{ml}$ round-bottomed flask equipped

Table 2. Synthesis of optically pure $\beta$-amino alcohol from optically pure propylene carbonate.

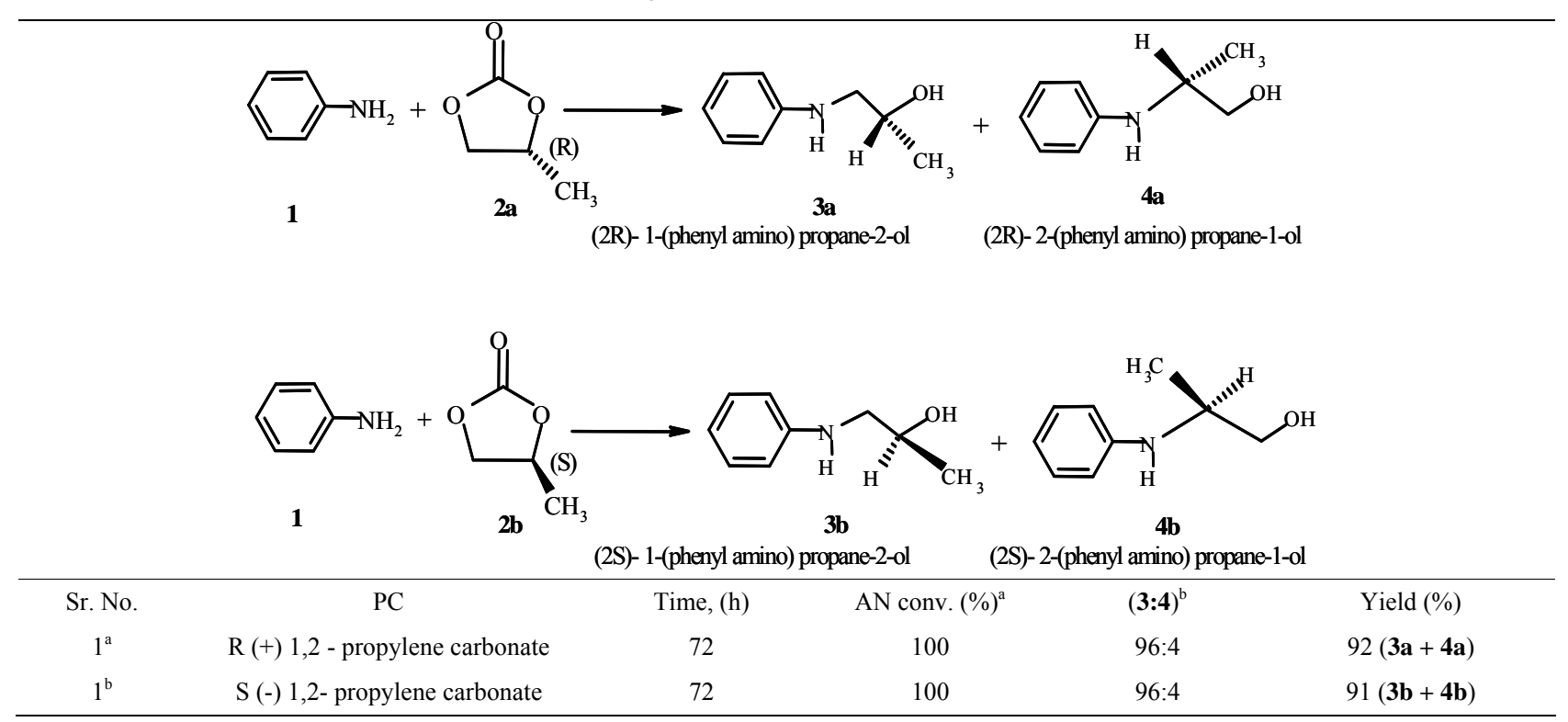

a conversion was determined by GC analysis and yield by HPLC; ${ }^{b}$ ratio was determined by GLC. 
with a magnetic stirring and reflux condenser was charged with $4.66 \mathrm{~g}$ (50.1 mmol) of aniline, $5.21 \mathrm{~g}$ (51.1 $\mathrm{mmol}$ ) of propylene carbonate and $0.10 \mathrm{~g} \mathrm{Na}-\mathrm{Y}$ zeolite as catalyst. The mixture was vigorously stirred at room temperature for $10 \mathrm{~min}$ and then mixture was heated at $150^{\circ} \mathrm{C}$. After reaction the viscous colorless liquid products were analyzed by gas chromatograph using Hewlett Packard 6890 Series GC equipped with auto sampler instrument, on a HP-5 capillary column $(30 \mathrm{~m} \times 320 \mu \mathrm{m}$ $\times 0.25 \mu \mathrm{m}$ film thickness, on a $5 \%$ phenyl methyl siloxane stationary phase).

After completion of reaction, reaction mixture was diluted with acetone and filtered (sartorius-393 grade filter paper) to separate the catalyst. More washings of acetone were given to the catalyst to remove adhered organic impurities. Then the catalyst was dried at $120^{\circ} \mathrm{C}$ for $24 \mathrm{~h}$ in vacuum oven, cooled and reused. The above procedure was repeated. This reusability of catalyst was done further five times and the reactant charges according to the amount of catalysts recovered keeping reactant to catalysts ratio same.

\subsection{Analytical Procedures}

About $300 \mathrm{mg}$ of the reaction crude diluted with acetone was coated on $\sim 3$ g column grade silica gel support (Gold Silica 20 - 40 m spherical; Catalog \# 60-5394-480; Purchased from RediSep ${ }^{\circledR}$ Media, USA) using rotary evaporator. Acetone is slowly evaporated under vacuum till the support changes to a free flowing powder which is than loaded onto the chromatogram instrument and the products were separated by flash chromatography on a 4 g normal phase silica RediSep ${ }^{\circledR}$ column employing nhexane-ethyl acetate as the eluent with gradient programming. Liquid chromatography was performed using Combi-Flash Companion, supplied by Teledyne ISCO, USA. 1-(phenylamino)propan-2-ol was thus isolated in pure form. Products were characterized and confirmed by GC-MS, IR and ${ }^{1} \mathrm{H}$ and ${ }^{13} \mathrm{C}$ NMR spectroscopy. Regio-selectivity of isomers was determined by GC and GC-MS analysis.

1-(phenylamino)propan-2-ol: ${ }^{1} \mathrm{H}$ NMR (200 MHz. $\mathrm{CDCl}_{3}$ ): $\delta=1.25$ (d, $J=6.3 \mathrm{~Hz}, 3 \mathrm{H} ;-\mathrm{CH}_{3}$ ); 2.64 (brs, $2 \mathrm{H}$; $\mathrm{NH} \& \mathrm{OH}) ; 2.98$ (dd, $J=8.4 \& 12.8 \mathrm{~Hz}, 1 \mathrm{H}$; -NCH- ); 3.21 (dd, $J=3.4 \& 12.8 \mathrm{~Hz}, 1 \mathrm{H}$; -NCH- ); 3.95 - 4.09 (m, 1H; -OCH- ); 6.64 - 6.67 (m, 3H; -CH, Ar); $7.15-7.25$ (m, 2H; -CH, Ar). ${ }^{13} \mathrm{C}$ NMR (50 MHz, $\left.\mathrm{CDCl}_{3}\right): \delta=20.74$ $\left(-\mathrm{CH}_{3}\right) ; 51.59\left(-\mathrm{NCH}_{2}\right) ; 66.28\left(-\mathrm{OCH}_{2}\right) ; 113.21(-\mathrm{CH}$, $\mathrm{Ar}) ; 117.83\left(-\mathrm{CH}_{3}, \mathrm{Ar}\right) ; 129.23(-\mathrm{CH}, \mathrm{Ar}) ; 148.12$ (-C, Ar). IR (film): $v_{\max }=3394(\mathrm{OH}, \mathrm{NH}), 2970(\mathrm{CH}), 1602$

Shimadzu

Sample ID : 1-ANILINO PROPANE-2-OL-RACEMIC Method name :C:ICLASS-VP]Methods Purity vp.met Accquisition time : 1/4/11 1:32:35 PM

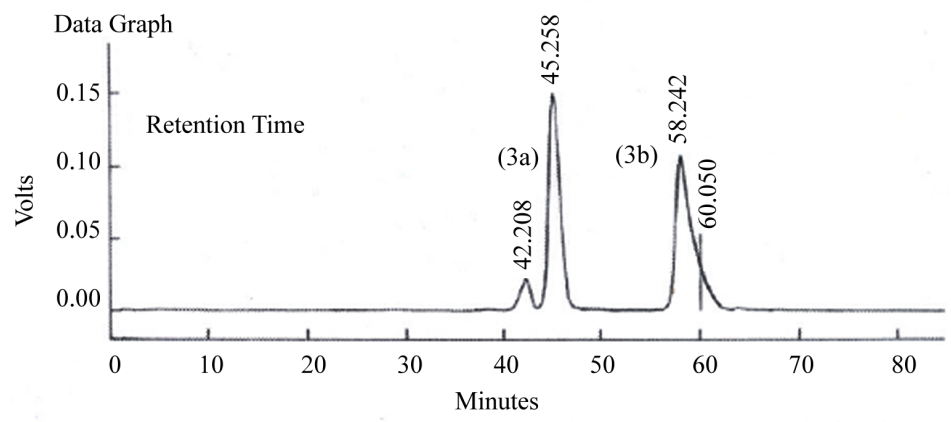

Run Report

Detector A - 1 (254 nm)

\begin{tabular}{cccc|}
\hline Pk\# & Reaction Time & Area & Area Percent \\
\hline 1 & 42.208 & 1586973 & 5.86 \\
2 & 45.258 & 11788271 & 43.54 \\
3 & 58.242 & 12004059 & 44.34 \\
4 & 60.050 & 1695226 & 6.26 \\
\hline Total & & & 100.00 \\
\hline
\end{tabular}

COLUMN : Chiral OD-H $25 \mathrm{~cm}$

MOBILE PHASE : IPA: PET ETHER 2.5:97.5

WAVELENGTH : $254 \mathrm{~nm}$

FLOW RATE : $1.0 \mathrm{ML} / \mathrm{MIN}$ 
Shimadzu

Sample ID : 1-ANILINO PROPANE-2-OL-R

Method name :C:ICLASS-VP\Methods\Purity vp.met

Accquisition time : 1/4/11 3:28:18 PM

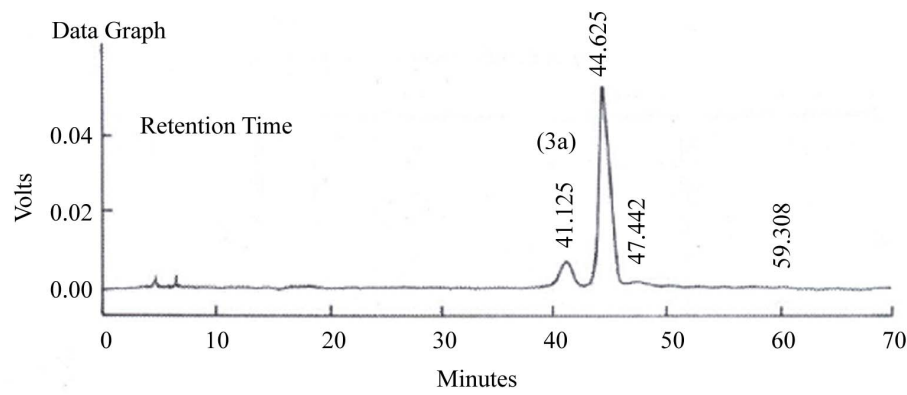

Run Report

Detector A - 1 (254 nm)

\begin{tabular}{ccrc} 
Pk\# & Reaction Time & Area & Area Percent \\
\hline 1 & 41.125 & 560699 & 11.67 \\
2 & 44.625 & 4026207 & 83.77 \\
3 & 47.442 & 185101 & 3.85 \\
4 & 59.308 & 34241 & 0.71 \\
\hline Total & & & 100 \\
\hline
\end{tabular}

COLUMN : Chiral OD-H $25 \mathrm{~cm}$

MOBILE PHASE : IPA: PET ETHER 2.5:97.5

WAVELENGTH : $254 \mathrm{~nm}$

FLOW RATE : $1.0 \mathrm{ML} / \mathrm{MIN}$

(b)

Shimadzu

Sample ID : 1-ANILINO PROPANE-2-OL-S

Method name :C:ICLASS-VP\Methods \Purity vp.met

Accquisition time : 1/4/11 6:12:15 PM

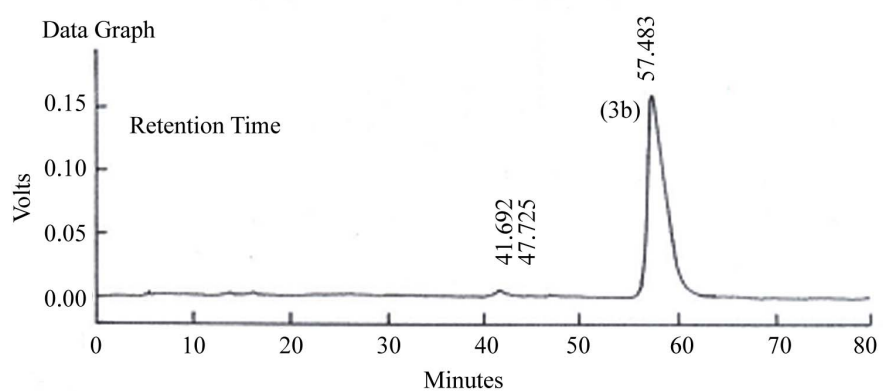

Run Report

Detector A - $1(254 \mathrm{~nm})$

\begin{tabular}{cccc|}
\hline Pk\# & Reaction Time & Area & Area Percent \\
\hline 1 & 41.692 & 356484 & 11.67 \\
2 & 44.725 & 144084 & 83.77 \\
3 & 57.483 & 20869714 & 3.85 \\
\hline Total & & 21370282 & 100 \\
\hline
\end{tabular}

COLUMN : Chiral OD-H $25 \mathrm{~cm}$

MOBILE PHASE : IPA: PET ETHER 2.5:97.5

WAVELENGTH : $254 \mathrm{~nm}$

FLOW RATE : $1.0 \mathrm{ML} / \mathrm{MIN}$

(c)

Figure 3. (a) Chiral HPLC Spectrum of racemic products (Major: 3a + 3b; minor: 4a + 4b; peak No. 2, 3, 1 and 4, respectively); (b) Chiral HPLC Spectrum of compound 3a ( $t, 44.625$ min); (c) Chiral HPLC Spectrum of compound $3 b$ ( $t$, 57.483 min). 
$(\mathrm{C}=\mathrm{C}, \mathrm{Ar}), 1506(\mathrm{C}=\mathrm{C}, \mathrm{Ar}) 1319(\mathrm{C}-\mathrm{N}, \mathrm{Ar})$ 1072, 750 $\mathrm{cm}^{-1}$. GC-MS (70 eV, EI) m/z (\%): 151 (21) $\left[\mathrm{M}^{+}\right], 106$ (100) $\left[\mathrm{C}_{6} \mathrm{H}_{5} \mathrm{NH}=\mathrm{CH}_{2}\right]^{+}, 93$ (2), 77 (16), 65 (2), 51 (5).

HPLC analysis of chiral products: Chiral amino alcohols could not be isolated in pure form; however they were analyzed using chiral HPLC collumn equipped with UV detector $(\lambda, 254 \mathrm{~nm})$. For this purpose racemic mixture of two regioisomers: $( \pm)$ 1-anilino propane 2-ol and $( \pm)$ 2anilino propane 1-ol obtained from reaction of $( \pm)$ 1,2propylene carbonate and aniline were analyzed by HPLC. The HPLC conditions used were: chiral column: Dicel ${ }^{\circledR}$ chiral OD-H; hexane: $i$-PrOH $(97.5: 2.5 \%, \mathrm{~V} / \mathrm{V})$, flow rate, $1 \mathrm{ml} / \mathrm{min} ; t_{1}=42.2 \mathrm{~min}$, 4a (minor); $t_{2}=45.2 \mathrm{~min}$, 3a (major); $t_{3}=58.2 \mathrm{~min}, 3 \mathbf{b}$ (major); $t_{4}=60.0 \mathrm{~min}, \mathbf{4 b}$ (minor); See Figures 3(a)-(c).

\subsection{Ion Exchange of Na-Y Zeolite}

One gram of Na-Y zeolite was exchanged with $25 \mathrm{ml}$, $1 \mathrm{M}$ ammonium acetate solution by stirring the mixture at $70^{\circ} \mathrm{C}$ for $1 \mathrm{~h}$. The extent of $\mathrm{Na}^{+}$exchange was monitored by number of exchanges carried out as desired. The ammonium form of zeolite was washed with distilled water several times, dried at $120^{\circ} \mathrm{C}$ overnight and calcined (under the flow of air at $540^{\circ} \mathrm{C}$ for $12 \mathrm{~h}$ by increasing the temperature from $\mathrm{RT}$ to $540^{\circ} \mathrm{C}$ at a rate of $3^{\circ} \mathrm{C} / \mathrm{min}$ ) to obtain $\mathrm{H}^{+}$form. The degree of exchange was determined by recording the absorbance intensity of $\mathrm{NH}_{4} \mathrm{NaY}$ exchanged samples in the range $2000-1000 \mathrm{~cm}^{-1}$. Bands at $1700 \mathrm{~cm}^{-1}, 1640 \mathrm{~cm}^{-1}, 1425 \mathrm{~cm}^{-1}$ and $1370 \mathrm{~cm}^{-1}$ due to $\mathrm{NH}$ bending modes were observed. The absorption at $1370 \mathrm{~cm}^{-1}$ was monitored for the purpose of calculating the amount of $\mathrm{NH}_{4}$ form of $\mathrm{NaY}$ zeolite. (the reported absorbance is at $1680 \mathrm{~cm}^{-1}, 1500 \mathrm{~cm}^{-1}, 1450 \mathrm{~cm}^{-1}$ and $1490 \mathrm{~cm}^{-1}$ for ammonia, adsorbed on HNaY zeolite, [43] in the present case, however, we believe that $\mathrm{NH}_{4} \mathrm{NaY}$ zeolite is synthesized by solid-liquid ion exchange process, the location of $\mathrm{NH}_{4}$ cation in zeolite frame-work is much more similar to $\mathrm{Na}$ location in original $\mathrm{NaY}$, while $\mathrm{NH}_{4} \mathrm{NaY}$ that is formed by adsorption of ammonia on $\mathrm{Si}-\mathrm{OH}-\mathrm{Al}$ groups of HNaY zeolite could have ammonium ion location close to $\mathrm{Si}-\mathrm{OH}-\mathrm{Al}$ group. Therefore, the interaction of $\mathrm{NH}_{4}$ cation with frame-work $\mathrm{Al}$ seems to differ from when $\mathrm{NH}_{4}$ cation that is formed by $\mathrm{NH}_{3}$ adsorption on $\mathrm{HNaY}$ and when by ion exchange of $\mathrm{NaY}$ zeolite). Three samples were thus prepared with degree of $\mathrm{H}^{+}$form, $18 \%, 55 \%$ and $90 \%$ respectively.

\section{Acknowledgements}

Assistance with FTIR and GCMS by Mrs. S. K. Shingate and making high quality tracings of chromatographs by Mr. P. A. Bhujang is greatly appreciated.

\section{References}

[1] B. M. Teresa, J. C. M. Adilia, C.D. Maycockd and T. Michaud, "Stereoselective Synthesis Of Optically Active Mono and Diaminoalcohols," Tetrahedron, Vol. 61, No. 33, 2005, pp. 7960-7966. doi:10.1016/j.tet.2005.06.011

[2] E. J. Corey and F. Zhang, "Re- and Si-Face-Selective Nitroaldol Reactions Catalyzed by a Rigid Chiral Quaternary Ammonium Salt: A Highly Stereoselective Synthesis of the HIV Protease Inhibitor Amprenavir (Vertex 478)," Angewandte Chemie International Edition, Vol. 38, No. 13-14, 1999, pp. 1931-1934. doi:10.1002/(SICI)1521-3773(19990712)38:13/14<1931: :AID-ANIE1931>3.0.CO;2-4

[3] C.W. Johannes, M.S. Visser, G. S. Weatherhead and A. H. Hoveyda, "Zr-Catalyzed Kinetic Resolution of Allylic Ethers and Mo-Catalyzed Chromene Formation in Synthesis: Enantioselective Total Synthesis of the Antihypertensive Agent $(S, R, R, R)$-Nebivolol," Journal of the American Chemical Society, Vol. 120, No. 33, 1998, pp. 8340-8347. doi:10.1021/ja9813780

[4] P. O'Brien, "Sharpless Asymmetric Aminohydroxylation: Scope, Limitations, and Use in Synthesis," Angewandte Chemie International Edition, Vol. 38, No. 3, 1999, pp. 326-329.

doi:10.1002/(SICI)1521-3773(19990201)38:3<326::AIDANIE326>3.0.CO;2-T

[5] G. Li, H. T. Chang and K. B. Sharpless, "Catalytic Asymmetric Aminohydroxylation (AA) of Olefins," Angewandte Chemie International Edition, Vol. 35, No. 4, 1996, pp. 451-454. doi:10.1002/anie.199604511

[6] D. J. Ager, I. Prakash and S. R. Schaad, "1,2-Amino Alcohols and Their Heterocyclic Derivatives as Chiral Auxiliaries in Asymmetric Synthesis," Chemical Review, Vol. 96, No. 2, 1996, pp. 835-876. doi:10.1021/cr9500038

[7] G. Huerta, G. C. Ordonez, C. Alvarez-Toledano, V. Santes, E. Gomez and R. A. Toscano, "Facile Synthesis of Aminoalcohols by Ring Opening of Epoxides under Solvent Free Conditions," Synth. Commun. 34:2393-2406 (2004). doi:10.1081/SCC-120039493

[8] S. W. Wei, K. A. Stingl, K. M. Weiss and S. B. Tsogoeva, "Bifunctional Organocatalysis with N-Formyl-L-Proline: A Novel Approach to Epoxide Ring Opening and Sulfide Oxidation," Synlett, Vol. 5, No. 5, 2010, pp. 707-711.

[9] D. M. Hodgson, A. R. Gibbs and G. P. Lee, "EnantioseleCtive Desymmetrisation Of Achiral Epoxides," Tetrahedron, Vol. 52, No. 46, 1996, pp. 14361-14384. doi:10.1016/0040-4020(96)00888-5

[10] R. M. Hanson, "The Synthetic Methodology of Nonracemic Glycidol and Related 2,3-Epoxy Alcohols," Chemical Review, Vol. 91, No. 4, 1991, pp. 437-475. doi: $10.1021 / \mathrm{cr} 00004 \mathrm{a} 001$

[11] A. S. Rao, S. K. Paknikar and J. G. Kirtane, "Recent Advances In The Preparation And Synthetic Applications Of Oxiranes," Tetrahedron, Vol. 39, No. 14, 1983, pp. 23232367. doi:10.1016/S0040-4020(01)91961-1

[12] G. H. Posner and D. Z. Rogers, "Organic Reactions at Alumina Surfaces. Mild and Selective Opening of Epox- 
ides by Alcohols, Thiols, Benzeneselenol, Amines, and Acetic Acid," Journal of the American Chemical Society, Vol. 99, No. 25, 1997, pp. 8214-8218.

[13] Y. Yamamoto, N. Asao, M. Meguro, N. Tsukade, H. Nemoto, N. Adayari, J. G. Wilson and H. Nakamura, "Regio- And Stereo-Selective Ring Opening Of Epoxides with Amide Cuprate Reagents," Journal of the Chemical Society, Chemical Communication, No. 15, 1993, pp. 1201-1202. doi:10.1039/c39930001201

[14] L. E. Overman and L. A. Flippin, "Facile Aminolysis Of Epoxides With Diethylaluminum Amides," Tetrahedron Letters, Vol. 22, No. 3, pp. 195-198. doi:10.1016/0040-4039(81)80053-6

[15] J. I. Yamada, M. Yumoto and Y. Yamamoto, "Aminolead Compounds As A New Reagent For Regioselective Ring Opening Of Epoxides," Tetrahedron Letters, Vol. 30, No. 32, 1989, pp. 4255-4258. doi:10.1016/S0040-4039(01)80704-8

[16] S. Sagava, H. Abe, Y. Hase and T. Inaba, "Catalytic Asymmetric Aminolysis of 3,5,8-Trioxabicyclo[5.1.0] Octane Providing an Optically Pure 2-Amino-1,3,4-butanetriol Equivalent," The Journal of Organic Chemistry, Vol. 64, No. 13, 1999, pp. 4962-4965. doi:10.1021/j09900883

[17] G. Sekar and Y. K. Singh, "An Efficient Method for Cleavage of Epoxides with Aromatic Amines," The Journal of Organic Chemistry, Vol. 64, No. 1, pp. 287-289. doi:10.1021/jo981196c

[18] J. Auge and F. Leroy, "Lithium TrifluoromethanesulFonate-Catalysed Aminolysis Of Oxiranes," Tetrahedron Letters, Vol. 37, No. 43, 1996, pp. 7715-7716. doi:10.1016/0040-4039(96)01731-5

[19] M. Chini, P. Crotti, L. Favero, F. Machhia and M. Pineschi, "Lanthanide(III) Trifluoromethanesulfonates as ExTraordinarily Effective New Catalysts for the Aminolysis of 1,2-Epoxides," Tetrahedron Letters, Vol. 35, No. 3, 1994, pp. 433-436. doi:10.1016/0040-4039(94)85073-9

[20] S. Chandrasekhar, T. Ramchander and P. S. Jaya, "TaCl $5_{5}$ Catalyzed Cleavage of Epoxides with Aromatic Amines," Synthesis, Vol. 13, 2000, pp. 1817-1818. doi: $10.1055 / \mathrm{s}-2000-8240$

[21] J. Iqbal and A. Pandey, "An Unusual Chemoselectivity in Cobalt(II) Chloride Catalysed Cleavage of Oxiranes with Anilines: A Highly Regioselective Synthesis of $\beta$-Amino alcohols," Tetrahedron Letters, Vol. 31, No. 4, 1990, pp. 575-576. doi:10.1016/0040-4039(90)87039-3

[22] M. Chini, P. Crotti and F. Macchia, "Metal Salts as New Catalysts for Mild and Efficient Aminolysis of Oxiranes," Tetrahedron Letters, Vol. 31, No. 32, 1990, pp. 46614664. doi:10.1016/S0040-4039(00)97701-3

[23] L. R. Reddy, M. A. Reddy, N. Bhanumathi and K. R. Rao, "Cerium Chloride-Catalysed Cleavage of Epoxides with Aromatic Amines," Synthesis, Vol. 6, 2001, pp. 831-832. doi:10.1055/s-2001-13414

[24] X. L. Fu and S. H. Wu, "A Regio- and Stereoselective Synthesis of $\beta$-Amino Alcohols," Synthetic Communication, Vol. 27, No. 10, 1997, pp. 1677-1683.

[25] P. van de Weghe and J. Collin, "Ring Opening Reactions
Of Epoxides Catalyzed By Samarium Iodides," Tetrahedron Letters, Vol. 36, No. 10, 1995, pp. 1649-1652 doi:10.1016/0040-4039(95)00086-R

[26] H. Kotsuki, K. Hayashida, T. Shimanouchi and H. Nishizawa, "High-Pressure Organic Chemistry. 19. High-Pressure-Promoted, Silica Gel-Catalyzed Reaction of Epoxides with Nitrogen Heterocycles," The Journal of Organic Chemistry, Vol. 61, No. 3, 1996, pp. 984-990.

[27] C. L. Kissel and B. Rickborn, "Base-Induced Rearrangement of Epoxides. IV. Reaction of Cyclohexene Oxide with Various Lithium Alkylamides," The Journal of Organic Chemistry, Vol. 37, No. 13, 1972, pp. 2060-2063. doi:10.1021/jo00978a002

[28] J. H. Clements, "Reactive Applications of Cyclic Alkylene Carbonates," Industrial \& Engineering Chemistry Research, Vol 42, No.4, 2004, pp. 663-674. doi: $10.1021 / \mathrm{ie} 020678 \mathrm{i}$

[29] C. B. Dartt and M. E. Davis, "Applications Of Zeolites To Fine Chemicals Synthesis," Catalysis Today, Vol. 19, No. 1, 1994, pp. 151-186. doi:10.1016/0920-5861(94)85006-2

[30] R. A. Sheldon and R. S. Downing, "Heterogeneous Catalytic Transformations for Environmentally Friendly Production," Applied Catalysis A: General, Vol. 189, No. 2 , 1999, pp. 163-183. doi:10.1016/S0926-860X(99)00274-4

[31] E. G. Derouane, "Zeolites as Solid Solvents," Journal of Molecular Catalysis A: Chemical, Vol. 134, No. 1-3, 1998, pp. 29-45. doi:10.1016/S1381-1169(98)00021-1

[32] A. B. Shivarkar, S. P. Gupte and R. V. Chaudhari, "Synthesis of $\beta$-Amino Alcohols from Aromatic Amines and Alkylene Carbonates Using Na-Y Zeolite Catalyst," Synlett, Vol. 9, No. 9, 2006, pp. 1374-1378.

[33] K. Tomishige, H. Yasuda, Y. Yoshida, M. Nurunnabi, B. $\mathrm{Li}$ and K. Kunimori, "Catalytic Performance and ProperTies of Ceria Based Catalysts for Cyclic Carbonate Synthesis from Glycol and Carbon Dioxide," Green Chemistry, Vol. 6, No. 4, 2004, pp. 206-214. doi: $10.1039 / \mathrm{b} 401215 \mathrm{a}$

[34] K. Tomishige, H. Yasuda, M. Nurunnabi, B. Li and K. Kunimori, "Selective Formation of Ethylene Carbonate From Ethylene Glycol and Carbon Dioxide over $\mathrm{CeO}_{2-}$ $\mathrm{ZrO}_{2}$ Solid Solution Catalysts," Studies in Surface Science and Catalysis, Vol. 153, 2004, pp. 165-168. doi:10.1016/S0167-2991(04)80239-8

[35] D. J. Barthomeuf, "Conjugate Acid-Base Pairs in Zeolites," The Journal of Physical Chemistry, Vol. 88, No.1, pp. 42-45. doi:10.1021/j150645a010

[36] M. Czijzek, T. Vogt and H. Fuess, "Aniline in Yb, Na-Y: A Neutron Powder Diffraction Study," Zeolites, Vol. 11, No. 8, 1991, pp. 832-836. doi:10.1016/S0144-2449(05)80064-8

[37] P. Enzel and T. Bein, "Inclusion of Polyaniline Filaments in Zeolite Molecular Sieves," The Journal of Physical Chemistry, Vol. 93, No. 17, 1989, pp. 6270-6272. doi: $10.1021 / \mathrm{j} 100354 \mathrm{a} 004$

[38] A. B. Shivarkar, S. P. Gupte and R. V. Chaudhari, "Tandem Synthesis of $\beta$-Amino Alcohols from Aniline, Dialkyl Carbonate, and Ethylene Glycol," Industrial \& Engi- 
neering Chemistry Research, Vol. 47, No. 8, 2008, pp. 2484-2494. doi:10.1021/ie070617q

[39] L. Saikia, J. K. Satyarthi, D. Srinivas and P. Ratnasamy, "Activation and Reactivity of Epoxides on Solid Acid Catalysts," Journal of Catalysis, Vol. 252, No. 2, 2007, pp. 148-160. doi:10.1016/j.jcat.2007.10.002

[40] A. K. Chakraborti and A. Kondaskar, " $\mathrm{Zrcl}_{4}$ as a New and Efficient Catalyst for the Opening of Epoxide Rings by Amines," Tetrahedron Letters, Vol. 44, No. 45, 2003, pp. 8315-8319. doi:10.1016/j.tetlet.2003.09.046

[41] P. N. Joshi, U. D. Joshi, T. H. Kim, K. I. Kim and V. P. Shiralkar, "The Compatibility of Compositional and Structural Features of Aluminous Large Pore Zeolites with Sorption Characteristics," Adsorption, Vol. 7, No. 4, 2001, pp. 279-289. doi:10.1023/A:1013120916684

[42] P. N. Joshi, A. A. Shaikh, V. R. Chumbhale, B. S. Rao and V. P. Shiralkar, "Crystallisation of Zeolite Mordenite and ZSM-5 without the Aid of a Template," Journal of Inclusion Phenomena and Macrocyclic Chemistry, Vol. 13, No. 2, 1992, pp. 171-179. doi:10.1007/BF01053641

[43] B. Hunger, H. Miessner, M. V. Szombathely and E. Geidel, "Heterogeneity of Si-OH-A1 Groups in HNaY Zeolites," Journal of the Chemical Society, Faraday Transactions, Vol. 92, No. 3, 1996, pp. 499-504.

doi:10.1039/ft9969200499 